\title{
EXISTENCE OF REGULAR NUT GRAPHS FOR DEGREE AT MOST 11
}

\author{
PATRICK W. FOWLER \\ Department of Chemistry \\ University of Sheffield, Sheffield, United Kingdom \\ e-mail: p.w.fowler@sheffield.ac.uk \\ John Baptist Gauci \\ Department of Mathematics \\ University of Malta, Msida, Malta \\ e-mail: john-baptist.gauci@um.edu.mt

\section{Jan Goedgebeur ${ }^{1}$} \\ Department of Applied Mathematics, Computer Science \& Statistics \\ Ghent University, Ghent, Belgium \\ Computer Science Department, \\ University of Mons, Mons, Belgium \\ e-mail: jan.goedgebeur@ugent.be \\ TOMAŽ PisAnski ${ }^{2}$ \\ Department of Information Sciences and Technologies \\ University of Primorska, Koper, Slovenia \\ Department of Mathematics, \\ University of Ljubljana, Ljubljana, Slovenia \\ e-mail: pisanski@upr.si
}

AND

\section{IRENE SCIRIHA}

Department of Mathematics

University of Malta, Msida, Malta

e-mail: irene.sciriha-aquilina@um.edu.mt

\footnotetext{
${ }^{1}$ Supported by a Postdoctoral Fellowship of the Research Foundation Flanders (FWO).

${ }^{2}$ Supported in part by the Slovenian Research Agency (research program P1-0294 and research projects N1-0032, J1-9187, J1-1690), and in part by H2020 Teaming InnoRenew CoE.
} 


\title{
Dedicated to the memory of Slobodan Simić.
}

\begin{abstract}
A nut graph is a singular graph with one-dimensional kernel and corresponding eigenvector with no zero elements. The problem of determining the orders $n$ for which $d$-regular nut graphs exist was recently posed by Gauci, Pisanski and Sciriha. These orders are known for $d \leq 4$. Here we solve the problem for all remaining cases $d \leq 11$ and determine the complete lists of all $d$-regular nut graphs of order $n$ for small values of $d$ and $n$. The existence or non-existence of small regular nut graphs is determined by a computer search. The main tool is a construction that produces, for any $d$-regular nut graph of order $n$, another $d$-regular nut graph of order $n+2 d$. If we are given a sufficient number of $d$-regular nut graphs of consecutive orders, called seed graphs, this construction may be applied in such a way that the existence of all $d$-regular nut graphs of higher orders is established. For even $d$ the orders $n$ are indeed consecutive, while for odd $d$ the orders $n$ are consecutive even numbers. Furthermore, necessary conditions for combinations of order and degree for vertex-transitive nut graphs are derived.
\end{abstract}

Keywords: nut graph, core graph, regular graph, nullity.

2010 Mathematics Subject Classification: 05C30, 05C50, 05C75, 05C90, $68 \mathrm{R} 10$.

\section{REFERENCES}

[1] G. Brinkmann, K. Coolsaet, J. Goedgebeur and H. Mélot, House of graphs: A database of interesting graphs, Discrete Appl. Math. 161 (2013) 311-314. doi:10.1016/j.dam.2012.07.018

[2] G. Brinkmann, J. Goedgebeur and B.D. McKay, Generation of cubic graphs, Discrete Math. Theor. Comput. Sci. 13 (2011) 69-80.

[3] K. Coolsaet, P.W. Fowler and J. Goedgebeur, homepage of Nutgen. http://caagt.ugent.be/nutgen/

[4] K. Coolsaet, P.W. Fowler and J. Goedgebeur, Generation and properties of nut graphs, MATCH Commun. Math. Comput. Chem. 80 (2018) 423-444.

[5] P.W. Fowler, B.T. Pickup, T.Z. Todorova, M. Borg and I. Sciriha, Omni-conducting and omni-insulating molecules, J. Chem. Phys. 140 (2014) 054115. doi:10.1063/1.4863559

[6] J.B. Gauci, T. Pisanski and I. Sciriha, Existence of regular nut graphs and the Fowler construction, (2019). arXiv preprint arXiv:1904.02229

[7] D. Holt and G.F. Royle, A census of small transitive groups and vertex-transitive graphs, J. Symbolic Comput. (2019), in press. doi:10.1016/j.jsc.2019.06.006 
[8] B.D. McKay and G.F. Royle, The transitive graphs with at most 26 vertices, Ars Combin. 30 (1990) 161-176.

[9] M. Meringer, Fast generation of regular graphs and construction of cages, J. Graph Theory 30 (1999) 137-146.

doi:10.1002/(SICI)1097-0118(199902)30:2〈137::AID-JGT7〉3.0.CO;2-G

[10] I. Sciriha, On the construction of graphs of nullity one, Discrete Math. 181 (1998) 193-211. doi:10.1016/S0012-365X(97)00036-8

[11] I. Sciriha, On the rank of graphs, in: Combinatorics, Graph Theory and Algorithms, Vol. II, Y. Alavi, D.R. Lick and A. Schwenk (Ed(s)), (Springer, Michigan, 1999) 769-778.

[12] I. Sciriha, A characterization of singular graphs, Electron. J. Linear Algebra 16 (2007) 451-462. doi:10.13001/1081-3810.1215

[13] I. Sciriha, Coalesced and embedded nut graphs in singular graphs, Ars Math. Contemp. 1 (2008) 20-31. doi:10.26493/1855-3974.20.7cc

[14] I. Sciriha and I. Gutman, Nut graphs: maximally extending cores, Util. Math. 54 (1998) 257-272.

Received 30 August 2019

Revised 6 November 2019

Accepted 7 November 2019 